\title{
Highly Stable Hydrogen Peroxide Biosensor Based on Gelatin- Hierarchical Porous Carbon Obtained from Fish Scales Modified Glassy Carbon Electrode
}

 \\ ${ }^{1}$ China National Center for Food Safety Risk Assessment, Beijing, P. R. China \\ ${ }^{2}$ State Key Laboratory of Chemical Resource Engineering, Beijing Laboratory of Biomedical \\ Materials, The Key Laboratory of Carbon Fiber and Functional Polymers, Ministry of Education, \\ Beijing University of Chemical Technology, Beijing, P. R. China \\ ${ }^{3}$ School of Information Management and Engineering, Shanghai University of Finance and \\ Economics, Shanghai, P. R. China \\ *E-mail: wanghuali@cfsa.net.cn, huangyq@mail.buct.edu.cn
}

doi: $10.20964 / 2017.07 .73$

Received: 9 March 2017 / Accepted: 7 May 2017 / Published: 12 June 2017

Biosensors for continuous application are becoming more important, and long-life enzyme electrodes have not been commercialized due to the lack of stability of its components. A highly stable biosensor for hydrogen peroxide $\left(\mathrm{H}_{2} \mathrm{O}_{2}\right)$ based on gelatin-hierarchical porous carbon obtained from fish scales has been developed in this work. Catalase (Cat) immobilized on gelatin-hierarchical porous carbon was realized by the adsorption-crosslinked, here glutaraldehyde (GAD) was used as cross-linking agent. The surface morphologies of modified glass carbon electrodes(GCE) were characterized by scanning electron microscopy (SEM), and the electrochemical behaviors of the biosensor were characterized by cyclic voltammogram $(\mathrm{CV})$ and electrochemical impedance spectroscopy (EIS). This biosensor exhibited a linear range from 0.2 to $10.7 \mathrm{mM}$ with a correlation coefficient $\left(\mathrm{R}^{2}\right)$ of 0.999 , a low detection limit of $0.7 \mu \mathrm{M}$ and a sensitivity of $74.69 \mu \mathrm{AmM}^{-1} \mathrm{~cm}^{-2}$. Especially, the stability of the as-prepared biosensor was satisfied at room temperature, which means there was almost no change in the performance even after 100 continuous scans, and the storage stability is over 30 days with retention of $98.7 \%$ activity only.

Keywords: Gelatin, Porous carbon, Operational and long-term stability, Catalase, Hydrogen peroxide biosensor

\section{$\underline{\text { FULL TEXT }}$}


(C) 2017 The Authors. Published by ESG (www.electrochemsci.org). This article is an open access article distributed under the terms and conditions of the Creative Commons Attribution license (http://creativecommons.org/licenses/by/4.0/). 